\section{Emergency eye care in rural Australia: role of internet}

\begin{abstract}
Purpose Significant differences exist in the utilization of emergency eye care services in rural and urban Australia. Meanwhile, influence of internet-based technology in emergency eye care service utilization has not been established. This study aims to demonstrate, from a health provider perspective, an internet-based service's impact on emergency eye care in rural Australia.

Methods The teleophthalmology service was initiated in the Carnarvon Regional Hospital (CRH) of the Gascoyne region in Western Australia. A digital, slit lamp and fundus camera were used for the service. Economic data was gathered from the Department of Health of Western Australia (DOHWA), the $\mathrm{CRH}$ and the Lions Eye Institute.

Results During the study period (JanuaryDecember, 2003) 118 persons took part in teleophthalmology consultations. Emergency cases constituted $3 \%$ of these consultations. Previous year, there were seven eye-related emergency evacuations (inter-hospital air transfers) from the Gascoyne region to City of Perth.

Conclusions Analysis demonstrates implementation of internet-based health services has a marked impact on rural emergency eye care delivery. Internet is well suited to ophthalmology for the diagnosis and management of acute conditions in remote areas. Integration of such services to mainstream health care is recommended. Eye (2006) 20, 1342-1344. doi:10.1038/sj.eye.6702104; published online 23 September 2005
\end{abstract}

Keywords: Healthcare evaluation; eye care; telemedicine

Received: 22 June 2005

Accepted in revised form:

4 August 2005

Published online:

23 September 2005

Conflict of interest statement: None

\author{
Introduction \\ Ophthalmologic accidents and emergencies are \\ an important component of a hospital
}

S Kumar ${ }^{1}$, K Yogesan'1 , B Hudson², M-L Tay-Kearney ${ }^{1}$ and IJ Constable ${ }^{1}$

workload, constituting $5 \%$ of all emergencies. ${ }^{1,2}$ The commonest diagnoses are corneal foreign bodies (20\%), corneal abrasions $(12 \%)$, and conjunctivitis $(8 \%) .^{3}$ The male to female ratio is $1: 88$, the excess being explained by the higher risk of injury in men (professional and domestic). ${ }^{2}$ Provision of emergency eye care for children is also important, although the apparent incidence is low. ${ }^{4}$ In rural areas, these patients are usually seen by general practitioners, who often lack confidence in the management of eye emergencies. The broad range of presenting cases often confronts for training and the organization of effective referral chains.

Analysis reveals that $50-70 \%$ of these referrals did not constitute accidents or urgent conditions and conditions could have been more properly assessed. ${ }^{5}$ Given this scenario, an internet-based system for eye care (teleophthalmology) may have potential for use in emergency eye care in rural and remote regions.

Teleophthalmology is one of the fastestevolving new technologies, providing the means for undertaking sophisticated eye care, and for keeping contact with patients in rural and remote areas. ${ }^{6}$ Despite the similarity in prevalence of eye disease in urban and rural areas, significant differences exist in the utilisation of eye care services in Australia. ${ }^{7}$

In the state of Western Australia, with a land area ten times larger than UK, ophthalmologists practice mostly in the capital city of Perth. ${ }^{8}$ Regular specialist visits to 15 rural and regional centers in the state happen only once or twice a year. When specialist eye care is required for people in the remote regions, often the patient must be transported to Perth.

It is suggested that telemedicine service may enhance health service delivery in rural areas. ${ }^{9}$ However, an internet-based service's influence on emergency eye care has not been established. Hence, this evaluation aims to demonstrate, from a health provider perspective, an internetbased service's impact on emergency eye care in rural Australia. 


\section{Methods}

An internet-based (www.e-icare.com) eye care service was initiated in the Carnarvon Regional Hospital (CRH) of the Gascoyne region in Western Australia. The Lions Eye Institute (LEI), Perth provided training to a rural nonmedical officer and organized eye-specialists in Perth to diagnose images sent through this internet system. Apart from emergency consultations, the program also conducted diagnosis and management of general eye-related diseases including glaucoma, diabetic retinopathy and trachoma. A digital, portable slit lamp, developed by $\mathrm{LEI}^{10}$ and a hand-held fundus camera (Canon CR4-45NM), were used for the telemedicine service.

Data relating to eye-related cost of care diagnostic to the Gascoyne population was gathered from the Department of Health of Western Australia (DOHWA), the CRH and the LEI. Ethical approval was obtained from the University of Western Australia Human Ethics Committee and the Western Australia Aboriginal Health Information Ethics Committee.

\section{Population and Setting}

The total Gascoyne population for 2001 was 10753 . It takes at least $2 \mathrm{~h}$ to fly or $11 \mathrm{~h}$ to drive from the nearest city of Perth $(940 \mathrm{~km})$. There are no eye-specialist services available in this region on a full-year basis. The current practice is for an eye specialist to visit the region for a week two times per year for consultations. Also, once a year, two specialists visit the region for a week to perform low complexity eye surgery, basically cataract cases.

\section{Results}

During the study period (Jananuary-December, 2003) 118 persons took part in teleophthalmology consultations (42\% men, 58\% women, Mean age 42 years, range 4-73 years). Average time of telemedicine consultation was 30 min per patient. Teleophthalmology service was utilized for primary eye care $(86 \%)$, secondary and follow-up care (11\%) and for emergency cases (3\%). A variety of ophthalmic conditions were dealt with during the study period (Table 1). Statistics for Carnarvon Regional Hospital for eye-related services (Table 2), exhibit a decline of approximately $15 \%$ in the number of occasions of service from 2002 to 2003.

There was no emergency air evacuation during the study period. For the same period in the previous year (2002), there were seven evacuations (inter-hospital air transfers) from the Gascoyne region to City of Perth (Table 3). Six of these seven evacuations had a priority
Table 1 Carnarvon Regional Hospital-list of ophthalmologic conditions consulted using teleophthalmology service in year 2003

\begin{tabular}{lc}
\hline Ophthalmic conditions & Number of cases \\
\hline Diabetic retinopathy & 43 \\
Glaucoma & 57 \\
Cataract & 6 \\
Trachoma & 0 \\
Trauma & 4 \\
Other & 8 \\
Total & 118 \\
\hline
\end{tabular}

Table 2 Carnarvon Regional Hospital-eye-related consultations at outpatient clinic 2001-2003

\begin{tabular}{lccc}
\hline Year & 2001 & 2002 & 2003 \\
\hline $\begin{array}{l}\text { Number of patients } \\
\text { \% Change }\end{array}$ & 455 & 485 & 412 \\
\hline
\end{tabular}

Table 3 Eye-related emergency evacuations from Carnarvon in 2002

\begin{tabular}{lcc}
\hline Initial diagnosis & Number of cases & Priority status $^{\mathrm{a}}$ \\
\hline Eye injury & 1 & 3 \\
Glaucoma & 1 & 1 \\
Foreign body & 1 & 3 \\
Corneal ulcer & 1 & 3 \\
Traumatic hyphema & 1 & 3 \\
Orbital cellulitis & 1 & 3 \\
Acute infection & 1 & 3 \\
Total number of evacuations & 7 & \\
\hline
\end{tabular}

apriority code status $1=$ urgent take-off, $2=$ take-off within $4 \mathrm{~h}$ or so, $3=$ take-off within $24-48 \mathrm{~h}$.

status of three, that is, take-off within 1 to 2 days, the lowest priority code for evacuations (Table 3).

The minimum cost of an air evacuation trip from the Gascoyne region to Perth is $\$ 7300$ (travel with a nurse). If hypothetically, these six priority three evacuations were avoided, savings to the system would amount to $\$ 40600$, assuming every trip was accompanied by a nurse only, that is, cost of avoiding six evacuations $(\$ 40602)=($ evacuation average cost $(\$ 7300)-$ teleconsultation cost (\$277) - Patient Assistance Travel Scheme: PATS average cost $(\$ 255)) \times 6$.

\section{Discussion}

Access to emergency treatment in rural areas can often mean the difference between life and death. ${ }^{11}$ Internetbased technologies have the potential to provide earlier 
diagnosis and intervention, save lives and avoid unnecessary transfers from rural hospital emergency departments to urban hospitals. ${ }^{12}$ Benefits for rural healthcare staff in skills acquisition and education are also evident. ${ }^{13}$ This evaluation study demonstrates the potential value of telemedicine use in rural eye care emergency.

There is a real need for ophthalmic emergency services in rural regional hospitals. The cheapest and most efficient way to diagnose these emergencies appears to be through internet service. A decline (15\%) in the number of eye related cases in CRH may be related to a number of people presenting themselves directly for the teleconsultation service.

While acknowledging that the time comparisons need to be more appropriate by comparing 'like-for-like', at $\mathrm{CRH}$, the average time of an internet consultation was 30 min against a $2-\mathrm{h}$ and 45 -min turnaround time for an emergency department evaluation. ${ }^{14}$ A variety of emergency complaints were managed effectively using relatively low-cost internet-based telemedicine technology, thereby eliminating the need for transportation of the patient to the emergency department in the city.

Specialist diagnostics is readily available and a better assessment of patient's evacuation urgency is made using the internet service available at $\mathrm{CRH}$. Other benefits included earlier diagnosis and intervention, a shorter stay in hospital (if hospitalization is deemed necessary) and avoided traveling for the patient.

Although acknowledging that conventional, face-toface consultation with a specialist doctor is beneficial; its cost is great in the remote regions. Internet services offer a substitution for conventionally provided emergency services in rural and remote regions. Furthermore, specialists are satisfied with this arrangement as it enhances their potential income, skill and practice, without disrupting conventional consultations at their urban hospital. ${ }^{15}$

\section{Conclusion}

Internet is well suited to ophthalmology for the diagnosis and management of acute conditions in remote areas. It offers considerable potential benefits to the patients, and enhances the skills of local practitioners. The implementation and integration of teleophthalmology services to the existing services will have an impact on current emergency eye care service utilization delivered for regional residents in Australia.

\section{Acknowledgements}

This work was supported by IPRS Scholarship from University of Western Australia. Authors are most grateful to the patients and clinical and administrative staff at Carnarvon Regional Hospital, Carnarvon for their cooperation with this study. We are also grateful to Francisco Chaves, Eric Dillon and Robyn Fary from Department of Health, Western Australia for their support during the study.

\section{References}

1 Bhopal RS, Parkin DW, Gillie RF, Han KH. Pattern of ophthalmological accidents and emergencies presenting to hospitals. J Epidemiol Commun Health 1993; 47: 382-387.

2 Girard B, Bourcier F, Agdabede I, Laroche L. Activity and epidemiology in an ophthalmological emergency center. $J$ de France d'Ophtalmol 2002; 25: 701-711.

3 Price M, Phillips CI. A general practitioner in an ophthalmology accident and emergency department. BMJ 1976; 2: 509-511.

4 Olver JM, Hague S. Children presenting to an ophthalmic casualty department. Eye 1989; 3(Part 4): 415-419.

5 Kheterpal S, Perry ME, McDonnell PJ. General practice referral letters to a regional ophthalmic accident and emergency department. Eye 1995; 9(Part 6 Suppl): 67-69.

6 Yogesan K, Cuypers M, Barry CJ, Constable IJ, Jitskaia. Tele-ophthalmology screening for retinal and anterior segment diseases. J Telemed Telecare 2000; 5: 96-98.

7 Keeffe JE, Weih LM, McCarty CA, Taylor HR. Utilisation of eye care services by urban and rural Australians. $\mathrm{Br} \mathrm{J}$ Ophthalmol 2002; 86: 24-27.

8 Wade M, Barry CJ, McAllister IL. Diabetic screening in remote Australian communities with a non-myriatic fundus camera. J Ophthalm Photo 1999; 4(2): 12-14.

9 Mitchell J. Increasing the cost-effectiveness of telemedicine by embracing e-health. J Telemed Telecare 2000; 6(Suppl 1): S16-S19.

10 Yogesan K, Cuypers M, Barry CJ, Constable IJ, Jitskaia L. Tele-ophthalmology screening for retinal and anterior segment diseases. J Telemed Telecare 2000; 5: 96-98.

11 Hicks LL, Boles KE, Hudson ST, Madsen RW, Kling B, Tracy $\mathrm{J}$ et al. Using telemedicine to avoid transfer of rural emergency department patients. J Rural Health 2001; 17(3): 220-228.

12 Tachakra S, Uche UC, Stinson A. Four years' experience of telemedicine support of a minor accident and treatment service. J Telemed Telecare 2002; 8(Suppl 2): 87-89.

13 Rosengren D, Blackwell N, Kelly G, Lenton L, Glastonbury $\mathrm{J}$. The use of telemedicine to treat ophthalmological emergencies in rural Australia. J Telemed Telecare 1998; 4(Suppl 1): 97-99.

14 Ellis DG, Mayrose J, Jehle DV, Moscati RM, Pierluisi GJ. A telemedicine model for emergency care in a short-term correctional facility. Telemed J E Health 2001; 7: 87-92.

15 Buckley D, Lower T. Factors influencing the utilisation of health services by rural men. Aust Health Rev 2002; 25: 11-15. 